\title{
Effects of ranitidine treatment on patients with asthma and a history of gastro-oesophageal reflux: a double blind crossover study
}

\author{
TOMMY EKSTRÖM，BJÖRN R LINDGREN，LITA TIBBLING \\ From the Departments of Lung Medicine and Otolaryngology, University Hospital, Linköping, Sweden
}

\begin{abstract}
Forty eight patients with moderate to severe asthma were enrolled in a double blind crossover study designed to evaluate the effects of ranitidine treatment, $150 \mathrm{mg}$ twice daily for four weeks, on gastro-oesophageal reflux, asthma control, and bronchial reactivity. All 48 had a history of reflux symptoms and 27 had in addition reflux associated respiratory symptoms. Thirty two patients had objective evidence of acid reflux on 24 hour $\mathrm{pH}$ monitoring ( $\mathrm{pH}$ of less than 4 for more than $1 \%$ of the 24 hours) and 27 patients had a positive result in the acid perfusion test. Reflux symptoms were significantly improved after ranitidine treatment. Ranitidine treatment was associated with modest improvements in nocturnal asthma and daily use of inhaled bronchodilator drugs but there was no significant change in bronchial reactivity, lung function, peak flow, or the number of eosinophils in the blood. Comparisons between the effect of ranitidine treatment on asthma control were performed between patients with and without a history of reflux associated respiratory symptoms, with and without a positive result in the acid perfusion test, and with and without objective evidence of gastrooesophageal reflux. A history of reflux associated respiratory symptoms was the only factor that predicted an improvement in asthma control after ranitidine treatment. These results indicate that antireflux treatment will produce only small improvements in asthma control in asthmatic patients with a history of gastro-oesophageal reflux.
\end{abstract}

\section{Introduction}

Gastro-oesophageal reflux may occur in as many as $30-60 \%$ of patients with asthma and other pulmonary disorders. ${ }^{1-5}$ It has been proposed that gastro-oesophageal reflux may cause or aggravate asthma, but the importance of this mechanism as a trigger factor has been poorly evaluated. Various pathways by which gastro-oesophageal reflux may trigger bronchospasm have been suggested, such as aspiration ${ }^{1-36-10}$ or an oesophago-bronchial reflex initiated by acid irritation of the oesophageal mucosa. "12 Acid stimulation of the oesophagus has been shown to increase bronchial reactivity. ${ }^{1314}$

In uncontrolled studies surgical treatment of gastrooesophageal reflux in asthmatic patients with a history suggestive of aspiration has improved asthma control..$^{7516}$ On the other hand, medical treatment of

Address for reprint requests: Dr Tommy Ekström, Department of Lung Medicine, University Hospital, S-582 85 Linköping, Sweden.

Accepted 1 October 1988 gastro-oesophageal reflux in patients with asthma and indirect signs of reflux has failed to produce any major effect on respiratory function. ${ }^{17}{ }^{18}$ It is not clear whether the ineffectiveness of medical treatment is due to insufficient prevention of reflux or to poor selection of asthmatic patients with respect to the severity of reflux.

The purpose of this investigation was to determine whether treatment with the $\mathrm{H}_{2}$ receptor antagonist ranitidine could improve asthma control or bronchial reactivity or both in a group of asthmatic patients with a history of gastro-oesophageal reflux, and whether any factors predicted which patients with asthma would benefit from antireflux treatment.

\section{Patients and methods}

Fifty patients with asthma and with symptoms of heartburn or acid regurgitation, or both, more than once a week gave informed consent to this study. The patients were selected with respect to their gastrooesophageal reflux symptoms from a population of 
Table 1 Current asthma medication of the 48 patients who completed the study (means with SEM or range)

M:F

Age (y)

Asthma duration (y)

Oral beta ${ }_{2}$ agonist $(\mathrm{mg} /$ day $)(\mathrm{n}=33)$

Theophylline $(\mathrm{mg} / \mathrm{day})(\mathrm{n}=26)$

Oral steroids $(\mathrm{mg} /$ day $)(\mathrm{n}=20)$

Inhaled steroids $(\mu \mathrm{g} /$ day $)(\mathrm{n}=32)$

350 patients with asthma attending the hospital outpatient clinic. All patients had also had asthmatic symptoms during the month before the study. Most patients had had moderate or severe asthma for several years and 20 of the 48 required oral corticosteroids to control their disease (table 1). The diagnosis of asthma was based on the criteria established by the American Thoracic Society. ${ }^{19}$ Twenty seven patients gave a history of one or more reflux associated respiratory symptoms - that is, a vague feeling of respiratory distress, wheeziness, or cough in connection with heartburn or acid regurgitation.

Before they entered the study an acid perfusion test ${ }^{20}$ and 24 hour $\mathrm{pH}$ monitoring ${ }^{21}$ of the distal oesophagus were performed. The acid perfusion test was considered to give a positive result if heartburn could be reproduced three times within 30 minutes and if the symptoms had been experienced during the last two weeks. A pH of less than 4 for more than $1 \%$ of 24 hours was considered to provide objective evidence of gastro-oesophageal reflux. ${ }^{21}$

Patients were given a four week supply of either ranitidine, $150 \mathrm{mg}$ to be taken twice daily, or an identical placebo in randomised order according to a double blind crossover design. The treatment periods were preceded by a two week run in period and followed by a two week washout period.

Patients recorded symptoms of asthma immediately on awakening in the morning, during the day, and at night in a diary for each day of the 12 weeks of the study. The patients also noted sensitivity to airborne irritants (such as perfume, smoke, and dust), reflux symptoms, and the level of physical activity during the day. All features were graded for average severity on a scale of $0-3$; zero indicated no symptoms and 3 the most severe symptoms. The daily use of inhaled bronchodilator drugs (number of puffs) and any change of regular medication were also recorded.

All current antireflux treatment was withdrawn at the start of the study but antacids were allowed when needed. The patients were provided with a mini Wright peak flow meter and were asked to make three measurements immediately on waking and before retiring in the evening. The highest value was recorded in the diary.

FEV , measurements, blood eosinophil counts, and histamine challenge tests were performed on the last $\overrightarrow{\vec{F}}$ day of each treatment period. A dry spirometer $\stackrel{?}{+}$ (Vitalograph, Buckingham) was used to measure $\mathrm{FEV}_{1}$ and the histamine provocation test was per- $\frac{\bar{\sigma}}{\bar{c}}$ formed by a method similar to that described by $\vec{\sigma}$ Cockcroft and coworkers. ${ }^{22} \mathrm{~A}$ jet nebuliser (Aiolos $\cong$ System, Karlstad, Sweden) was used with a constant output of $0.7 \mathrm{ml} / \mathrm{min}$; it gave an average particle size of $\vec{\circ}$ $4 \mu \mathrm{m}$. Change in $\mathrm{FEV}_{1}$ was plotted against log dose histamine and the dose that caused a $20 \%$ fall in FEV,$\vec{\omega}$ $\left(\mathrm{PC}_{20}\right)$ was determined by interpolation.

\section{STATISTICAL ANALYSIS}

$\mathrm{PC}_{20}$ values were log transformed before analysis. Wilcoxon's signed rank test was used to compare $\overrightarrow{0}$ mean symptom scores and peak flow (PEF) values $\stackrel{\circ}{-}$ over the four weeks that the patient received ranitidine or placebo. The Mann-Whitney $U$ test was used for comparing subgroups. A three way analysis of variance was used to determine which factors used to divide patients into subgroups predicted a response to ranitidine treatment.

\section{Results}

Forty eight patients completed both test periods. The mean (SEM) percentage of the 24 hours of monitoring in which reflux was shown to be present $(\mathrm{pH}<4)$ was $\varrho$ $4.4(0.6)$. Thirty two patients had objective evidence of $\overrightarrow{\vec{O}}$ reflux as categorised above from 24 hour $\mathrm{pH}$ monitor- 3 ing and 27 patients had a positive result in the acid perfusion test. Two patients were withdrawn from the study owing to poor compliance with the study protocol.

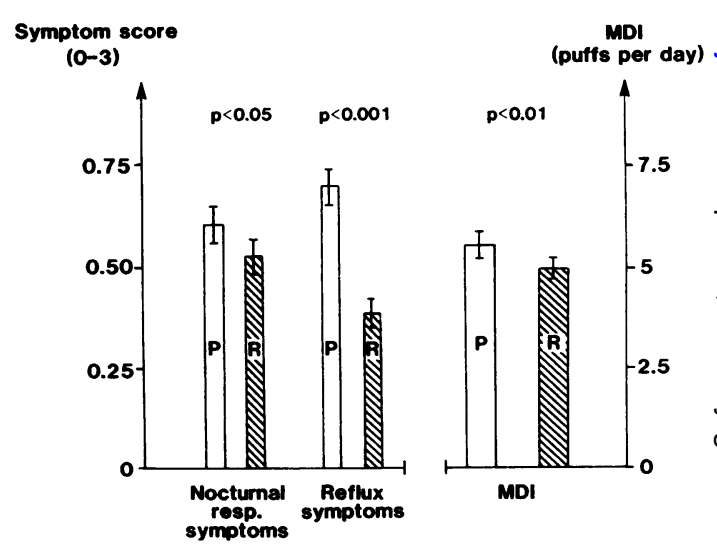

Differences (mean and SEM values) in reflux and nocturnal respiratory symptoms and consumption (number of puffs) of beta ${ }_{2}$ agonist metered dose inhalers (MDI) between placebo $(P)$ and ranitidine $(R)$ treatment in 48 patients with asthma and a history of gastro-oesophageal reflux. 
Table 2 Measurements (mean (SEM) values) during placebo and ranitidine treatment periods in 48 patients with asthma

\begin{tabular}{|c|c|c|c|c|c|}
\hline Measurement & Placebo & & Ranitidi & & $p$ \\
\hline 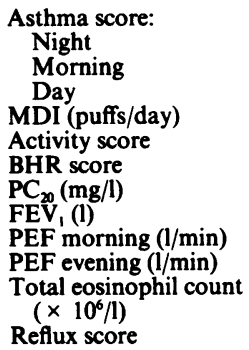 & $\begin{array}{l}0.61 \\
0.87 \\
0.73 \\
5 \cdot 6 \\
0.73 \\
0.33 \\
0.28 \\
2.26 \\
374 \\
409\end{array}$ & $\begin{array}{l}(0.09) \\
(0.08) \\
(0.09) \\
(0.60) \\
(0.10) \\
(0.08) \\
(0.13) \\
(0.12) \\
(16) \\
(15)\end{array}$ & $\begin{array}{c}0.53 \\
0.82 \\
0.67 \\
5.0 \\
0.64 \\
0.33 \\
0.20 \\
2.31 \\
380 \\
417 \\
297 \\
0.39\end{array}$ & $\begin{array}{l}(0.08) \\
(0.09) \\
(0.09) \\
(0.56) \\
(0.10) \\
(0.08) \\
(0.05) \\
(0.10) \\
(15) \\
(15)\end{array}$ & $\begin{array}{l}0.02 \\
0.58 \\
0.50 \\
0.006 \\
0.18 \\
0.81 \\
0.69 \\
0.51 \\
0.61 \\
0.33\end{array}$ \\
\hline
\end{tabular}

$\mathrm{PC}_{20}$ - concentration of histamine producing a fall in $\mathrm{FEV}_{1}$ of $20 \%$; FEV - - forced expiratory volume in one second; PEF-peak expiratory flow; MDI-metered dose inhaler; BHR score-bronchial hyperreactivity symptom score.

Reflux symptoms were significantly improved after ranitidine treatment (figure). There were also significant though clinically modest differences in nocturnal respiratory symptoms and inhaled beta ${ }_{2}$ adrenoceptor agonist requirements between the ranitidine and placebo treatment periods (figure). Respiratory symptoms in the morning and during the day, physical activity, histamine $\mathrm{PC}_{20}$ values, $\mathrm{FEV}, \mathrm{PEF}$, and the number of blood eosinophils did not differ significantly between the placebo and ranitidine treatment periods (table 2). Complete relief of asthma symptoms was not seen in any patient during ranitidine treatment. Patients with severe and poorly controlled asthma did not respond more favourable to antireflux treatment than patients with more stable disease.

Patients were divided into two subgroups according to whether they did or did not have a history of reflux associated respiratory symptoms, whether they had or did not have a positive result in the acid perfusion test, and whether they had a total reflux time of more than $1 \%$ of the day or of up to $1 \%$. The most pronounced improvements in respiratory symptoms with ranitidine were found in the subgroup with a history of reflux associated respiratory symptoms (RARS +; $\mathrm{n}=27$; table 3 ). Patients without a history of reflux associated respiratory symptoms (RARS $-; \mathbf{n}=21$ ) showed no response to ranitidine treatment (table 3). Reflux associated respiratory symptoms were not found significantly more often in those with a positive result in the acid perfusion test $(63 \%)$ than in those with a negative result $(48 \%)$ or in those with objective evidence of reflux $(63 \%)$ than in those without $(44 \%)$. When patients with a positive and a negative result in the acid perfusion test and those with gastrooesophageal reflux for more than $1 \%$ and for up to $1 \%$ of the day were compared there were no significant
Table 3 Comparisons (mean (SEM) values) between placebo and ranitidine treatment in patients with a history of reflux associated respiratory symptoms $(R A R S+)$ and in patients without (RARS-)

\begin{tabular}{llllll}
\hline & \multicolumn{2}{l}{$R A R S+(n=27)$} & & $R A R S-(n=21)$ \\
\cline { 2 - 3 } \cline { 5 - 6 } & Placebo & Ranitidine & Placebo & Ranitidine \\
\hline Night score & $0.71(0.12)$ & $\begin{array}{l}0.52 \\
(0.11)^{* * *}\end{array}$ & $0.49(0.13)$ & $0.53(0.14) \mathrm{NS}$ \\
MDI puffs/day & $5.9(0.92)$ & $5.2(0.88)^{*}$ & $5.3(0.71)$ & $4.8(0.62) \mathrm{NS}$ \\
Reflux score & $0.73(0.10)$ & 0.37 & $0.62(0.18)$ & $0.38(0.15) \mathrm{NS}$ \\
& & $(0.07)^{* * *}$ & & \\
\hline
\end{tabular}

${ }^{*} \mathrm{p}<0.05 ;{ }^{* * *} \mathrm{p}<0.001$.

Only measurements with significant differences between ranitidine and placebo treatment periods are given.

MDI-metered dose inhaler.

differences for any of the respiratory assessments.

There was no significant difference in the use of concomitant asthma medication between the two treatment periods (table 1). Symptom scores and PEF values did not differ significantly between run in and washout periods. No adverse clinical events were recorded during ranitidine treatment.

\section{Discussion}

Antireflux treatment with the $\mathrm{H}_{2}$ receptor antagonist ranitidine was associated with a substantial reduction in reflux symptoms and a small improvement in nocturnal respiratory symptoms and daily use of inhaled bronchodilator drugs. Objective measurements of lung function and bronchial reactivity were not affected by ranitidine treatment.

The efficacy of medical antireflux treatment on the symptoms of asthma has been reported by other authors. $^{782324}$ Objective improvement in respiratory function has, however, been lacking or, when shown, it has not been impressive. ${ }^{24}$ In agreement with our findings, Goodall et $a l^{18}$ showed improvement of nocturnal respiratory symptoms after cimetidine treatment, whereas the overall effect on asthma was minimal. The relatively modest effect of medical antireflux treatment on asthma control in our study could be explained by insufficient prevention of reflux despite substantial effects on heartburn and regurgitation symptoms. The effects of ranitidine on gastrooesophageal reflux were not assessed objectively but previous studies have shown that ranitidine reduces gastric acid secretion, causing total reflux time to be decreased, ${ }^{25}$ though not completely abolished. It can also be argued that any benefit of ranitidine treatment may have been partly blunted as the patients were allowed to use antacids during the placebo period. Such a pronounced reduction in reflux symptoms was observed, however, after ranitidine treatment that if gastro-oesophageal reflux really triggers asthma in a 
clinically important way it should have been detected. A complete restriction of antacids during the trial would have been difficult to control as most of these drugs are available without prescription. It is also possible that the respiratory symptoms of our patients were too mild and that a population with a higher mean symptom score might have yielded more positive results. Our study, like others, rather suggests that gastro-oesophageal reflux in the vast majority of asthmatic patients is a weak trigger factor for asthma, causing only mild respiratory symptoms in those patients in whom there is a causal relation between episodes of reflux and the respiratory disease. The influence of reflux on asthma is predominantly seen at night, when the airways are more hyperreactive and susceptible to stimulation.

The subgrouping used in this study was an attempt to identify asthmatic patients who might benefit most from antireflux treatment. A positive result in the acid perfusion test (a sign of acid sensitive oesophagus) is said to be a prerequisite for the occurrence of reflex bronchoconstriction after oesophageal acid stimulation. ${ }^{12} \mathrm{~A}$ long total reflux time will increase the acid contact time in the oesophagus and increase the likelihood that aspiration could occur. Neither a positive result in the acid perfusion test nor objective evidence of gastro-oesophageal reflux predicted which patients with asthma would respond to antireflux treatment. A history of reflux associated respiratory symptoms was the only factor that identified patients whose asthma control improved with ranitidine treatment. Even in this selected group of patients, however, the effect of antireflux treatment on asthma was small. Thus the patient's history rather than oesophageal investigations seems to be the most accurate and simple way to select patients with asthma for antireflux treatment. Asymptomatic or so called silent reflux is likely to be less important than symptomatic reflux as a trigger of asthma in adults.

Our study lends no support to the hypothesis that gastro-oesophageal reflux will increase airway responsiveness, as has been suggested by others. ${ }^{1314} \mathrm{H}_{2}$ receptor blockers may, however, affect histamine induced bronchoconstriction, though this is disputed. Some authors have found a slight potentiation of histamine responsiveness in asthmatic patients with cimetidine ${ }^{26}$ but others have found no effect ${ }^{27} 28$ and Eiser $e t a l^{9}$ showed a small but significant inhibitory effect from intravenous cimetidine. We found no difference in histamine reactivity between placebo and ranitidine treatment periods.

In conclusion, when possible trigger factors in asthma are being evaluated a careful history of reflux symptoms should be taken and antireflux treatment should be considered in patients with reflux associated respiratory symptoms. Antireflux treatment is unlikely to have a large effect on asthma control, but it $\overrightarrow{\vec{B}}$ should relieve heartburn and other reflux symptoms.

This study was supported by grants from the Swedish Medical Research Council (project No 17X-0426015A) and Glaxo Pharmaceutical Company.

\section{References}

1 Klotz SD, Moeller RK. Hiatal hernia and intractable bronchial asthma. Ann Allergy 1971;29:325-8.

2 Friedland GW, Yamate M, Marinkovich VA. Hiatal i hernia and chronic unremitting asthma. Pediatr Radiol 1973;1:150-60.

3 Mays EE. Intrinsic asthma in adults: association with gastroesophageal reflux. JAMA 1976;236:2626-8.

4 Shapiro GG, Christie DL. Gastroesophageal reflux in steroid dependent asthmatic youths. Pediatrics 1979; 63:207-12.

5 Martin ME, Grunstein MM, Larsen GL. The relation-? ship of gastroesophageal reflux to nocturnal wheezing in children with asthma. Ann Allergy 1982;49:318-22. $\overrightarrow{0}$

6 Pellegrini CA, DeMeester TR, Johnson LF, Skinner DB. Gastroesophageal reflux and pulmonary aspiration: incidence, functional abnormality, and results of sur-O gical therapy. Surgery 1979;86:110-9.

7 Berquist WE, Rachelefsky GS, Kadden M, et al. GER-⿳亠二口 associated recurrent pneumonia and chronic asthma in children. Pediatrics 1981;68:29-35.

8 Greyson ND, Reid RH, Liu YC, et al. Radionuclide $\overrightarrow{\vec{F}}$ assessment in nocturnal asthma. Clin Nucl Med 1982;윽 7:318-9.

9 Bengtsson U, Sandberg N, Bake B, et al. Gastro-oeso phageal reflux and night-time asthma [letter]. Lancet 1985;i:1501-2.

10 Veyrac $M$, Bories $\mathrm{P}$, Collet $\mathrm{H}$, et al. Scintigraphie et $\frac{\mathrm{O}}{\mathrm{O}}$ pHmetrie oesophagienne chez des adultes asthma- $x$ tiques suspects de reflux gastro-oesophagien. Gastro-O enterol Clin Biol 1986;10:400-4.

11 Mansfield LE, Stein MR. Gastroesophageal reflux and $\delta$ asthma: a possible reflex mechanism. Ann Allergy 1978; 41:224-6.

12 Spaulding HS, Mansfield LE, Stein MR, Sellner JC, Gremillion DE. Further investigation of the associa $\frac{7}{0}$ tion between gastroesophageal reflux and broncho을 constriction. J Allergy Clin Immunol 1982;69:516-21. N

13 Wilson NM, Charette L, Thomson A, Silverman M:Gastro-oesophageal refiux and childhood asthma: the $\mathcal{N}$ acid test. Thorax 1985;40:592-7.

14 Herve P, Denjean A, Jian R, Simonneau G, Duroux P Intraesophageal perfusion of acid increases the bronchomotor response to metacholine and to isocapnice hyperventilation in asthmatic subjects. Am Rev Respire Dis 1986;134:986-9.

15 Foglia RP, Fonkalsrud EW, Ament ME, et al. Gastroesophageal fundoplication for the management of chronic pulmonary disease in children. Am J Surgo 1980;140:72-9.

16 Perrin-Fayole M, Bel A, Braillon G, et al. Asthme et reflux gastro-oesophagien. Resultats de la cure chirur=- 
gicale chez 50 malades. Poumon-Coeur 1980;36:231-7.

17 Kjellén G, Tibbling L, Wranne B. Effect of conservative treatment of oesophageal dysfunction on bronchial asthma. Eur J Respir Dis 1981;62:190-7.

18 Goodall RJR, Earis JE, Cooper DN, Bernstein A, Temple JG. Relationship between asthma and gastrooesophageal reflux. Thorax 1981;36:116-21.

19 American Thoracic Society. Definitions and classification of chronic bronchitis, asthma and pulmonary emphysema. Am Rev Respir Dis 1962;85:762-8.

20 Bernstein LM, Baker LA. A clinical test for esophagitis. Gastroenterology 1958;34:760-81.

21 Johansson K-E, Boeryd B, Fransson S-G, Tibbling L. Oesophageal reflux tests, manometry, endoscopy, biopsy and radiology in healthy subjects. Scand $J$ Gastroenterol 1986;21:399-406.

22 Cockcroft DW, Killian DN, Mellon JJA, Hargreave FE. Bronchial reactivity to inhaled histamine: a method and clinical survey. Clin Allergy 1977;7:235-43.

23 Ramon P, Mallart-Voisin A, Wallaert B, et al. Association asthma et reflux gastro-oesophagien: strategie des explorations paracliniques. Rev Mal Respir 1985;2:
289-94.

24 Harper PC, Bergner A, Kaye MD. Antireflux treatment for asthma. Improvement in patients with associated gastroesophageal reflux. Arch Intern Med 1987;147: $56-60$.

25 Johansson K-E, Tibbling L. Gastric secretion and reflux pattern in reflux oesophagitis before and during ranitidine treatment. Scand J Gastroenterol 1986;21: 487-92.

26 Nathan RA, Segall N, Glover GC, Schocket AL. The effects of $\mathrm{H}_{1}$ and $\mathrm{H}_{2}$ antihistamines on histamine inhalation challenges in asthmatic patients. Am Rev Respir Dis 1979;120:1251-9.

27 Thomson NC, Kerr JW. Effect of inhaled $\mathbf{H}_{1}$ - and $\mathbf{H}_{2}$ receptor antagonists in normal and asthmatic subjects. Thorax 1980;35:428-34.

28 Nogrady SG, Bevan C. $\mathrm{H}_{2}$-receptor blockade and bronchial hyperreactivity to histamine in asthma. Thorax 1981;36:268-71.

29 Eiser NM, Mills J, Snashall PD, Guz A. The role of histamine receptors in asthma. Clin Sci 1981;60: 363-70. 